\title{
A vigilância sanitária em Feira de Santana no processo de descentralização da saúde (1998-2000)
}

\author{
The sanitary surveillance in Feira de Santana \\ in the health decentralization process (1998-2000)
}

Iraildes Andrade Juliano 1

Marluce Maria Araújo Assis 1

\footnotetext{
1 Departamento de Saúde.

Núcleo de Pesquisa

Integrada em Saúde Coletiva (NUPISC).

Av. Universitária,

Km 3 -BR 116 -

Norte. 44100-000

Feira de Santana BA.

nupisc@bol.com.br
}

\begin{abstract}
This study analyses the organization of the Sanitary Surveillance of Feira de Santana (VISA) in the process of health decentralization (1998-2000), pointing out the advances and limits on the local stage. It is an exploratory study, of qualitative approach, in a historic-social perspective whose spatial area was the Sanitary Vigilance Division of the municipal Health Department. The statements made by managers, technicians, sanitary inspectors and documentary sources made up the empirical material. The analysis made clear the absence of a political project for the decentralized management of VISA's actions in the local government. It points limits: (dis)articulation from the regional level, temporary human resources and without technical qualification, the difficulties in the use of the financial incentive, infrastructure insufficiency and political interfering. The study emphasizes advances: fulfillment of the Agreed and Integrated Programming, listing of the establishments subject to sanitary control, inter-institutional articulation. This projec needs the mobilization of members of society that have the ability to speak up so to give the project a priority agenda, in favor of life quality. Key words Sanitary surveillance, Descentralization of health, Health rigths
\end{abstract}

Resumo Este estudo analisa a organização da Vigilância Sanitária (Visa) de Feira de Santana no processo de descentralização da saúde (19982000), apontando avanços e limites no cenário local. Trata-se de um estudo exploratório, de abordagem qualitativa, numa perspectiva históricosocial, cujo recorte espacial foi a Divisão de Vigilância Sanitária da Secretaria Municipal de Saúde. Os materiais empíricos foram os depoimentos de gestores, técnicos, inspetores sanitários e fontes documentais. A análise evidenciou a ausência de um projeto político para a gestão descentralizada das ações de Visa no município. Aponta limites: (des)articulação com o nível regional, recursos humanos temporários e sem qualificação técnica, dificuldades na utilização do incentivo financeiro, insuficiência de infra-estrutura e interferências políticas. Destaca avanços: cumprimento da Programação Pactuada e Integrada, cadastramento dos estabelecimentos sujeitos à fiscalização sanitária, articulações interinstitucionais. Esse processo necessita da mobilização de sujeitos sociais com capacidade de vocalização para inscrevêlo numa agenda de prioridades, em prol da qualidade de vida da população.

Palavras-chave Vigilância Sanitária, Descentralização da Saúde Direito à Saúde 


\section{Introdução}

O presente estudo tem como objeto de análise a organização do componente municipal de Vigilância Sanitária de Feira de Santana (BA), tomando como eixo orientador o processo de descentralização da saúde, no período de 19982000, apontando limites e avanços no cenário do sistema local de saúde.

$\mathrm{O}$ atual conceito de vigilância sanitária está presente na Lei Orgânica da Saúde (LOS $8.080 / 90$, art. 6o, parágrafo 1 o), que a considera um conjunto de ações capazes de eliminar, diminuir ou prevenir riscos à saúde e de intervir nos problemas sanitários decorrentes do meio ambiente, da produção e circulação de bens e da prestação de serviços de interesse para a saúde (Carvalho \& Santos, 1995). Dessa forma, além de introduzir o conceito de risco, a LOS ampliou a intervenção do Estado no processo saúde-doença e em seus determinantes e condicionantes, configurando a vigilância sanitária na conflitante arena das forças produtivas.

Segundo Costa (1999a), a vigilância sanitária conforma um campo singular de articulações complexas entre o domínio econômico, o jurídico e o médico sanitário, responsável pelo controle de riscos e prevenção de danos à saúde relacionados com o consumo de produtos, tecnologias e serviços de interesse sanitário, que podem ser decorrentes de defeitos ou falhas de fabricação, falhas de diagnóstico, inadequação da prescrição, dentre outras, e de atitudes ilícitas de fabricantes, comerciantes ou prestadores de serviços.

Dentre as oito atribuições do Sistema Único de Saúde (SUS), seis se referem ao campo específico da vigilância sanitária, o que denota a amplitude e a magnitude das suas ações na consolidação desse sistema. As ações de vigilância sanitária permeiam, portanto, as ações de promoção da saúde, proteção, recuperação e reabilitação.

Não obstante, o modelo institucional de vigilância sanitária desenvolvido no país vem mantendo-se calcado no poder de polícia perceptível na ação fiscalizatória, isolado das demais ações de saúde e pouco permeável aos movimentos sociais (Costa, 1999b) e isto tem produzido um viés que limita a atuação da vigilância sanitária, restringindo-a ao próprio "poder de polícia".

$\mathrm{O}$ que se constata freqüentemente, através da mídia, é que os serviços de vigilância sanitária ainda não conseguem dar conta da sua ga- ma de atribuições, resultando em graves conseqüências no estado de saúde da população brasileira, em decorrência da falta de estruturação desses serviços, que por sua vez se ressentem de uma atuação mais efetiva.

O município de Feira de Santana, espaço de realização do presente estudo, integra o SUS com o Estado e a União de acordo com as diretrizes estabelecidas na sua Lei Orgânica Municipal no 037/90 (Feira de Santana, 2000a), e encontra-se habilitado na Gestão Plena da Atenção Básica, nos termos da NOB/SUS 96 (Brasil, 1996a).

Em estudo realizado por Assis (1998a) no referido município, identificamos que o processo de municipalização da saúde em Feira de Santana vem sendo construído com incipiente participação da sociedade civil organizada, com avanços e recuos, na dependência do poder político conjuntural, apontando para um projeto institucional e burocrático subordinado ao ideário neoliberal. É neste contexto que se situa o campo da Vigilância Sanitária municipal, uma arena de conflitos e contradições, permeada por implicações econômicas, jurídicas, políticas, éticas e sociais, onde penetramos para desvendar os elementos que conformaram a sua organização, como parte do processo de descentralização da saúde.

\section{O processo de descentralização e o sistema federativo}

No plano mais geral, o Brasil, sistema federativo estruturado em três níveis político-administrativos - União, Estados e Municípios -, está dividido em 27 Estados e possui 5.561 municípios, com população aproximada de $170 \mathrm{mi}-$ lhões de habitantes, conforme o Censo Demográfico de 2000 (IBGE, 2003), o que já justifica a adoção da descentralização como viabilizadora das políticas públicas, por apresentar características muito complexas e desiguais que se manifestam nas diferenças socioeconômicas, culturais, demográficas e sanitárias entre suas diferentes regiões.

Viana, Lima \& Oliveira (2002) ao discutirem a questão do federalismo sinalizam que é preciso observar as relações entre governo central/unidades periféricas para que se compreenda a dinâmica da intervenção pública e que se identifiquem as variáveis que interferem nesse processo. Aquelas relações têm sido analisadas teoricamente, tomando como eixos orientado- 
res três modelos de federalismo: o dual, o cooperativo e o competitivo. No entanto, é preciso compreender que os modelos devem relacionar, também, a variedade de princípios federais dentro de cada federação e as circunstâncias históricas, econômicas, políticas e culturais de cada região. Em suma, a variável independente dos modelos federativos é a dinâmica da intervenção pública em cada contexto (Viana, Lima \& Oliveira, 2002) e, não somente, a discussão abstrata e ideal dos tipos de federalismo, pois segundo os autores não contribui efetivamente com as análises sobre as políticas públicas.

Até mesmo porque o federalismo se apresenta no Brasil como uma instituição que atenua as diferenças e disparidades inter e intraregionais, conformando um sistema federativo contraditório que constrange o nível central e reordena o papel dos governos estaduais e municipais na provisão dos serviços sociais, gerando uma diversidade de demandas e respostas aos problemas nacionais.

Os autores acima citados, inspirados em Kugelmas \& Sola, identificam três grandes períodos que traduzem a situação brasileira: 1o período, centralizador, retratado no regime militar-autoritário (dos anos 60 aos 70); 2o período, formador de um novo modelo federalista orientado para a descentralização (anos 80); e o 3o, indefinido quanto ao modelo de federação, mas com traços de recentralização e ausência marcante de mecanismos cooperativos, denominado de federalismo predatório, vigente nos anos 90 .

É importante ressaltar que o panorama mais geral do processo de descentralização dos anos 90 no Brasil vem sendo acompanhado de uma crescente fragmentação da gestão do social e de uma frágil base de sustentação fiscal dos Estados da Federação (Soares, 2000; Viana, Lima \& Oliveira, 2002).

Soares (2000) lança a provocação de que a descentralização pode ser denominada como "destrutiva" (em boa parte dos países latinoamericanos, inclusive Brasil), argumentando que, se por um lado, tem-se o desmonte de políticas sociais sem substituí-las; por outro, se delega aos municípios as competências sem os recursos correspondentes e/ou necessários. Essas políticas vêm gerando um profundo desequilíbrio na já complicada federação brasileira, retirando dos estados como entes federativos de maior porte as possibilidades financeiras, técnicas e políticas de planejar e coordenar programas sociais de forma regional e mais eqüitativa. Afirma, ainda, que a delegação de auto- ridade ao poder local, via descentralização com participação da sociedade, só se efetivaria de fato por meio de esforços ao combate do "coronelismo" e "caciquismo", ou seja, o combate aos esquemas tradicionais de poder das elites locais.

Nesse jogo contraditório, de interesses e de diferenças regionais e locais, não há, portanto, um modelo único de descentralização, pois as desigualdades regionais e a história de cada contexto, com seus diferentes sujeitos sociais e cenários específicos e singulares, conformam modelos diferenciados de descentralização. E ao tomar o campo da saúde, como eixo de análise, não se pode negar que há mais de duas décadas o Brasil vem experimentando reformas e reordenamento do seu sistema de saúde, na busca de uma nova ordem social, fundada nos princípios da universalidade, integralidade e descentralização.

\section{O processo de descentralização na saúde e a vigilância sanitária}

No setor saúde, é possível perceber uma certa diferenciação em relação ao processo mais amplo do modelo de descentralização brasileiro, já que não podemos negar que os anos 90 marcaram efetivamente a construção estratégica do processo político descentralizador do sistema de saúde, em que se buscou o cumprimento da LOS 8.080/90 (art.16, XV) (Carvalho \& Santos, 1995) e os seus desdobramentos com a Norma Operacional Básica (NOB-SUS 01/93), a Norma Operacional Básica (NOB-SUS 01/96) e a Norma Operacional de Assistência à Saúde (NOAS - 2001). (Andrade, 2001; Brasil, 2002; Arretche, 2003; Ugá et al., 2003).

O processo de descentralização do SUS com as referidas normas (nesse trabalho trataremos mais especificamente da NOB-SUS 01/96, por contemplar o objeto e o recorte temporal do estudo) possibilitaram a implementação de medidas que fortaleceram a gestão local.

No entanto, Ugá et al. (2003) ressaltam limites iniciais na sua operacionalização, caracterizados por um forte viés municipalista, cabendo às secretarias estaduais um papel secundário no processo. Argumentam, ainda, a intensificação dos conflitos de forma horizontal entre os municípios com o cerceamento de demandas por atendimento à saúde, advindas de municípios vizinhos, com comprometimento da solidariedade e do compartilhamento das respon- 
sabilidades de gestão. Esses limites vêm sendo superados gradativamente, à medida que se ajustam às diferentes responsabilidades da União, Estados e Municípios com critérios e parâmetros definidos pelo Ministério da Saúde, pelas Comissões Intergestores e Conselhos de Saúde.

A NOB-SUS 01/96 organiza o processo de gestão em modalidades, envolvendo estados e municípios: as modalidades de gestão plena da atenção básica e gestão plena do sistema, para os municípios; e as modalidades de gestão avançada do sistema e gestão plena do sistema para os estados, com repasse automático de recursos do Fundo Nacional de Saúde para os Fundos Estaduais e Municipais de Saúde. Essas formas de gestão se diferenciam em nível de responsabilidade, conferindo autonomia ao gestor municipal na gestão plena do sistema, para gerir o sistema como um todo, abarcando as ações relativas à promoção, proteção e recuperação da saúde. A gestão plena da atenção básica responsabiliza o gestor municipal pelas ações de atenção básica, que é caracterizada pela equalização das transferências de recursos por base populacional, através do Piso de Atenção Básica (PAB), compreendendo uma parte fixa, calculada com base em um valor per capita de R\$10,00, multiplicado pelo tamanho da população e uma parte variável, destinada ao estímulo financeiro à implementação dos programas, incluindo também as ações básicas de vigilância sanitária. Em dezembro de 2000, o percentual de municípios habilitados em alguma condição de gestão na NOB-96 chega a $99 \%$, sendo 523 municípios habilitados na condição de gestão plena $(9,5 \%)$ do sistema (Viana, Lima \& Oliveira, 2002).

Um dispositivo importante implementado a partir da NOB-SUS/96 se refere à Programação Pactuada e Integrada (PPI), que pretende romper com o modelo anterior de prestação de serviço e fixações de cotas por procedimentos. As práticas passam a ser reagrupadas em subgrupos constituídos por critérios de complexidade tecnológica, formulados com base nas especialidades profissionais e equipamentos necessários à realização das intervenções assistenciais (Brasil, 2002). Esse dispositivo pretende fugir da lógica indiscriminada de serviços ofertados pela iniciativa privada para permitir uma distribuição territorial mais justa e eqüitativa de recursos, vislumbrando articular os serviços e práticas do sistema e as redes de atenção à saúde do nível local e regional.

$\mathrm{Na}$ construção do processo de descentralização político-administrativa, é criado o Siste- ma Nacional de Vigilância Sanitária (SNVS), antiga demanda reivindicada por técnicos e organizações da sociedade civil relacionados à área de vigilância sanitária, sob as diretrizes da portaria 1.565, de 26 de agosto de 1994 (Brasil, 1994), cuja organização buscava a descentralização da execução dos serviços e ações da União para os Estados e Municípios, e dos Estados para os Municípios e instâncias regionais, definindo o SNVS e sua abrangência, esclarecendo a competência das três esferas de governo, estabelecendo as bases para a descentralização da execução de serviços e ações de vigilância em saúde no âmbito do SUS.

Posteriormente, com a criação da Anvisa (Brasil, 1999a) e o processo em curso de descentralização das ações e serviços de saúde, abremse novas perspectivas de avanços na realização das práticas de vigilância sanitária em nosso país e, conseqüentemente, da possibilidade de se efetivar a garantia do direito à saúde.

Atualmente, compete ao órgão federal (Anvisa) as atividades referentes à normatização e controle da produção e circulação de produtos e de força de trabalho, e aos outros níveis, as atividades referentes aos estabelecimentos comerciais, aos serviços de saúde, à fiscalização no comércio e a pequena produção, especialmente de alimentos, bem como as escassas iniciativas em relação ao ambiente (Costa, 1999b).

A partir desses elementos, é necessário compreender que no processo de descentralização das ações de vigilância sanitária deve ser considerada a natureza das questões que permeiam essa área, cujas ações devem estar integradas de acordo com as especificidades e competências dos níveis de gestão, não se restringindo, portanto, à noção de imediata transposição dessas ações.

Para análise do processo de gestão descentralizada das ações de vigilância sanitária no município de Feira de Santana, incorporamos a descentralização da saúde como um processo social, determinado pelo contexto histórico e político, marcado pela transferência de poder decisório para o nível local, no sentido de fortalecer o papel protagônico do município no exercício da responsabilidade sanitária.

\section{Metodologia do estudo}

Trata-se de um estudo exploratório de abordagem qualitativa, numa perspectiva históricosocial, cujo recorte espacial foi a Divisão de Vi- 
gilância Sanitária da Secretaria Municipal de Saúde de Feira de Santana (BA).

As ações básicas de Vigilância Sanitária são desenvolvidas atualmente pela Divisão de Vigilância Sanitária (Divisa), cabendo à Segunda Diretoria Regional de Saúde (2a Dires) a fiscalização das ações de média e alta complexidade em cooperação técnica com o órgão estadual de fiscalização (Diretoria de Vigilância e Controle Sanitário/Divisa/Sesab), além do processo de supervisão das ações básicas desenvolvidas pelo componente municipal de Visa (Feira de Santana, 1997).

Os sujeitos do estudo foram os trabalhadores em atividade no componente municipal de Vigilância Sanitária, bem como aqueles que ocuparam o cargo de gestor da saúde e/ou da Divisa no município; os técnicos em Visa (2), profissionais de nível superior em exercício profissional e inspetores sanitários (2), funcionários efetivos lotados na Divisa, com nível elementar e fundamental de escolaridade. Foram incluídos alguns informantes-chave (6), de acordo com as revelações do campo, cujas contribuições foram relevantes para a investigação. Buscamos esclarecer os referidos sujeitos acerca dos objetivos da investigação, solicitando aos que concordassem em participar do estudo que assinassem um Termo de Consentimento Livre e Esclarecido (Brasil, 2000) com o intuito de assegurar o anonimato do autor das falas e o sigilo das informações relatadas.

Utilizamos no trabalho de campo a técnica de entrevista semi-estruturada. O roteiro constou de informações acerca do participante do estudo, aspectos da organização e do processo de descentralização da Visa do município, sobre a política local de saúde e a inserção da Visa nessa política, assim como os limites e avanços dessas ações. As entrevistas foram realizadas no segundo semestre de 2000 e início de 2001, e de acordo com a disponibilidade dos sujeitos. Os dados secundários foram obtidos pelo levantamento documental, por constituirse, também, numa valiosa técnica de abordagem de material qualitativo (Philips, 1974, apud Lüdke \& André, 1986).

Para a análise dos dados, tomamos como referência a proposta hermenêutico-dialética, sistematizada por Minayo (1994) como um $\mathrm{ca}$ minho do pensamento. A união destas duas concepções, segundo a autora, busca $o$ texto, a fala, o depoimento como resultado de um processo social (trabalho e dominação) e processo de conhecimento (expresso em linguagem), ambos frutos de múltiplas determinações, mas com significados específicos. Para operacionalização da proposta procedemos à organização do conjunto de material obtido através das entrevistas e da análise documental: Organizamos o material selecionando aqueles referentes aos depoimentos dos sujeitos entrevistados e os conteúdos provenientes dos documentos, no sentido de confrontar as falas dos diversos sujeitos e de complementar as evidências captadas no cenário social investigado.

\section{Vigilância sanitária no processo de descentralização da saúde: o contexto de Feira de Santana}

Feira de Santana localiza-se no Recôncavo Baiano, distante 108 quilômetros da capital do Estado (Salvador) e ocupa uma base territorial de $1.344 \mathrm{~km}^{2}$, sendo considerada um dos mais importantes Centros regionais, com uma população de 480.949 habitantes, conforme censo demográfico de 2000 (IBGE, 2003). É o 2o pólo econômico do Estado, tendo o comércio como principal atividade econômica, seguida da pecuária, agricultura e indústria. Também conhecida como a Capital do Sertão, representa um dos maiores eixos rodoviários do país.

No ano de 1997, Feira de Santana disponibilizava 160 instituições de saúde (38 públicas e 122 privadas). As públicas detinham apenas $23,7 \%$ da capacidade instalada, enquanto as privadas respondiam por $76,3 \%$, ou seja, estavam com a administração de grande parte dos serviços. Do total de instituições existentes em Feira de Santana, a atenção básica representava 21\% (Assis, 1998b).

Em 2002, conforme Martins \& Assis (2002), as instituições privadas representavam 167 $(79,9 \%)$ e as públicas $42(20,1 \%)$ do total de 209 instituições no município. As policlínicas representavam 59\% (117 unidades) e os centros de saúde $18 \%$ (38 unidades), do total de instituições de saúde (públicas e privadas). Percebe-se que o modelo de atenção à saúde adotado no município vem privilegiando o modelo médico-centrado, realizado pela valorização da oferta de serviço em policlínicas. Do total (209) de instituições de saúde públicas e privadas de Feira de Santana a rede básica pública respondia por $18 \%$, ainda que se tenha uma pequena ampliação da capacidade instalada dos serviços públicos, de 38 unidades em 1997 para 42 unidades em 2002, em torno de $10 \%$. 
Em julho de 1997, o município habilita-se para a Gestão Plena de Atenção Básica. Contudo, foi a partir de 1998 que a SMS passou por um significativo período de transição, necessário ao processo de mudança, com a crescente incorporação de ações sob sua responsabilidade. O município precisava "entrar no eixo" do processo de municipalização das ações, que vinha tomando impulso não apenas aqui, como em todo o país.

Ao verificar a situação atual do processo de descentralização no país e no Estado da Bahia (Quadro 1), constatamos que a maioria dos municípios (Brasil-99,00\%; Bahia-98,80\%) já se encontravam habilitados em uma das condições de gestão estabelecidas pela NOB-96, passando a assumir, desta forma, a responsabilidade pela assistência à saúde dos seus munícipes, ampliando as possibilidades de descentralização das ações de vigilância sanitária.

Feira de Santana não poderia ficar à margem desse contexto e, desta forma, como gestor, adotou prioritariamente investir na reestruturação física da rede básica e na organização gerencial do Sistema Municipal de Saúde, no sentido de reorganizar os serviços, modificando a sua lógica assistencial. Procedeu, então, à aquisição de recursos materiais, ampliação das ações de responsabilidade da Rede Básica de Saúde como programas de saúde, farmácia básica, atendimento médico e a contratação de recursos humanos.

\section{O financiamento das ações de vigilância sanitária}

Em maio de 1998, o Ministério da Saúde inicia a transferência do Piso Básico de Vigilância Sanitária (PBVS) para o Fundo Municipal de Saúde de Feira de Santana. A partir de 2000, o município passa a receber, mensalmente, incentivo financeiro correspondente a $\mathrm{R} \$ 9.999,83$ destinados ao financiamento das ações básicas de vigilância sanitária e controle sanitário em produtos, serviços e ambientes sujeitos à vigilância, bem como às atividades de educação sanitária. No entanto, foi revelado pelos entrevistados que a equipe da SMS não estava segura acerca da utilização daquele recurso financeiro, e em quais despesas de custeio e de capital ele poderia ser aplicado.

Esses questionamentos não ocorreram apenas em Feira de Santana. A implementação do Piso de Atenção Básica (PAB), a partir de 1998, impulsionou o processo de descentralização em todo o país, ao garantir aos municípios um montante mínimo de recursos transferidos regular e automaticamente, já discutido anteriormente, permitindo ao gestor municipal assumir as responsabilidades que lhe competiam. De posse desse montante, grande número de gestores buscou esclarecimentos com as instâncias competentes do SUS no nível estadual e federal.

Os recursos financeiros do PAB deveriam ser utilizados apenas em despesas de custeio e capital relacionadas entre as responsabilidades definidas para a gestão da atenção básica, conforme o Manual da Atenção Básica (Brasil, 1999b), e em consonância com as diretrizes do Plano Municipal de Saúde. Tarefa árdua para o município de Feira de Santana, que, até então, não vinha priorizando as ações de vigilância sanitária como instrumento de gestão, conforme constatado na convergência das falas dos sujeitos entrevistados.

O quadro 2 apresenta o total de recursos financeiros repassados ao Fundo Municipal de Saúde de Feira de Santana, referente ao Piso Básico de Vigilância Sanitária, a partir do mês de maio de 1998 até o final do ano 2000.

Considerando o montante de recursos recebidos pelo município no período de 1998 a 2000 ( $\mathrm{R}$ \$ 343.819,15), os avanços no nível estrutural poderiam ter sido muito mais substantivos. O PBVS é transferido diretamente para a conta do FMS, onde fica "diluído" juntamente

\section{Quadro 1}

Situação dos municípios habilitados por condição de gestão - Brasil/Bahia. Dezembro, 2000.

\begin{tabular}{lcccc}
\hline União/Estado & No de Municípios & Atenção Básica & $\begin{array}{c}\text { Plena Sistema } \\
\text { Municipal }\end{array}$ & $\begin{array}{c}\text { Total Pleitos } \\
\text { Aprovados }\end{array}$ \\
\hline Brasil & 5.506 & $4.928(89,50 \%)$ & $523(9,50 \%)$ & $5.451(99,00 \%)$ \\
Bahia & 415 & $398(95,90 \%)$ & $12(2,89 \%)$ & $410(98,80)$ \\
\hline
\end{tabular}

Fonte: Ministério da Saúde/Secretaria de Assistência à Saúde (Brasil, 2001). 
com os demais recursos provenientes do PAB Fixo.

A partir das orientações do Manual da Atenção Básica, no início de 1999, novos investimentos foram empreendidos pela SMS, no sentido da estruturação dos serviços e fortalecimento da rede básica. Com o intuito de concentrar esforços para a reorganização da Divisa, a SMS, por intermédio da Diretoria de Saúde, propôs-se a definir uma política de Vigilância Sanitária. Nesse sentido, buscou-se articulação com a Academia (UEFS), que se materializou com a elaboração do Prodivisa - Projeto de Reestruturação da Divisão de Vigilância Sanitária da SMS (Juliano, 1999). Após a aprovação do CMS e antes mesmo da formalização do convênio entre as instituições envolvidas, foram iniciados os primeiros passos para a execução do projeto, através da realização de uma Oficina de Trabalho com a Equipe da Divisa. Contudo, o Prodivisa foi abruptamente interrompido, devido ao clima de instabilidade política que se havia instalado no município, num contexto de crise, permeado por acusações de corrupções e fraudes, direcionadas ao chefe do Executivo Municipal (prefeito), que teve o seu mandato ameaçado até mesmo de impeachment, porém, sem êxito.

Diante da crise que se instalou no final de 1999, ocorreram novas mudanças na condução político-administrativa da SMS resultando na indicação de um novo Secretário de Saúde, que também fez substituições nos cargos de diretores de saúde, dos departamentos e dos chefes de divisões.

\section{Recursos humanos da vigilância sanitária do município}

A SMS começou a incorporar novos profissionais à estrutura da Divisa, em decorrência das exigências do processo de descentralização das ações de vigilância sanitária, que já estava começando a tomar corpo no município.

A partir da segunda metade da década de 1990, a Divisa tem ampliado o número de inspetores sanitários e de novos profissionais de nível superior por meio de contrato temporário. Reconhecemos, como os sujeitos entrevistados, que a "ampliação do quadro de recursos humanos" representou um avanço na estrutura organizativa da Divisa. Contudo, a forma de inserção destes novos atores por meio de contrato temporário implica o enfrentamento de

\section{Quadro 2}

Transferência efetuada por competência (mês/ano) ao Fundo Municipal de Saúde de Feira de Santana, correspondente ao Piso Básico de Vigilância Sanitária (PBVS), no período de 1998-2000.

\begin{tabular}{lc}
\hline Mês/ano de competência & PBVS Subtotal \\
\hline 5 a $12 / 1998$ & $105.753,12$ \\
1 a $12 / 1999$ & $118.068,07$ \\
1 a $12 / 2000$ & $119.997,96$ \\
Total & $343.819,15$ \\
\hline
\end{tabular}

Fonte: Ministério da Saúde/Datasus, 2000.

uma série de limitações, do ponto de vista da continuidade das atividades realizadas, de investimento de recursos na capacitação de pessoal provisório, além de contrariar o mandamento constitucional que estabelece que a investidura em cargo ou emprego público depende de aprovação prévia em concurso público de provas ou de provas e títulos (CF/88, art. 37, II), reservando-se os casos de contratação por tempo determinado para atender a "necessidade temporária de excepcional interesse público" (art. 37, IX). (Brasil, 1996b).

Posteriormente, em junho de 2000, foi realizado concurso público para o preenchimento de vagas na SMS, para médicos, cirurgiõesdentistas e enfermeiros, porém isto não se fez acompanhar do incremento de profissionais efetivos na Divisa.

Verificamos, portanto, que a partir de 1998, a SMS começou a acrescentar, de forma gradual, novos profissionais à Divisa, em decorrência do processo de descentralização e do conseqüente repasse de recursos financeiros (PBVS), chegando a apresentar um incremento de 135\% no quadro de recursos humanos da Divisa entre 1998-2000, como pode ser visualizado no quadro 3.

Estes dados evidenciam uma "bipolarização profissional" (Médici et al., 1992) entre os profissionais de nível superior (farmacêuticos, médicos, enfermeiros), em relação aos de nível elementar (inspetores sanitários) lotados na Divisa, refletindo uma característica presente no mercado de trabalho em saúde nos países capitalistas, onde existe um maior contingente de pessoal pouco qualificado e de baixa escolaridade, com salários mais baixos em detrimento da qualidade dos serviços prestados à população.

Do total de funcionários da Divisa em 1998, 13 eram efetivos (um de nível superior e 12 de 
Quadro 3

Distribuição do quantitativo de recursos humanos da Divisão de Vigilância Sanitária Municipal (DIVISA), por categoria profissional. 1998-2000. Feira de Santana. Maio/2001.

\begin{tabular}{lcc}
\hline Categoria Profissional & $\mathbf{1 9 9 8}$ & $\mathbf{2 0 0 0}$ \\
\hline Farmacêutica-Bioquímica & 01 & 01 \\
Socióloga Sanitarista & 01 & - \\
Enfermeira & 01 & 01 \\
Médico-Veterinário & 01 & 03 \\
Médica & - & 01 \\
Engenheiro Agrônomo & - & 01 \\
Inspetor Sanitário & 12 & 32 \\
Auxiliar de Serviços Gerais & 01 & 01 \\
Total & 17 & 40
\end{tabular}

Fonte: SMS - Divisão de Vigilância Sanitária Municipal.

nível elementar) e quatro contratados (apenas dois de nível superior). Em 2000, observa-se a incorporação de 25 novos agentes, inseridos por meio de contratos temporários.

Com relação ao treinamento e capacitação de recursos humanos da SMS, consta do Relatório de Gestão de 1998 a intenção de capacitar seu quadro de pessoal à nova realidade organizacional exigida pelo processo de municipalização. Esse relatório apresenta, apenas, o quantitativo de recursos humanos da SMS, sem fazer referências a processos educativos promovidos no decorrer de 1998, o que pode ser explicado pela inexistência de um plano de capacitação para a instituição, muito embora a estruturação de um sistema de educação continuada tivesse sido uma das estratégias estabelecidas no Plano Municipal de Saúde (Feira de Santana, 1997b), para a implementação de uma política de desenvolvimento de recursos humanos.

Todavia, ao analisar o Relatório de Gestão de 2000 (Feira de Santana, 2000b), detectamos, no item referente ao Programa de Educação Continuada, ausência de referência à realização de ações educativas direcionadas à equipe da Divisa. Não obstante, ao confrontar estas informações com o Relatório Anual da Divisa deste mesmo ano, verificamos que a equipe participou de cursos de treinamento e capacitação promovidos por outras instituições: Universidade, Laboratório Central-BA (Lacen), 2a Dires e Secretaria Estadual de Saúde (Sesab).

Mesmo estando habilitado na Gestão Plena da Atenção Básica, e apesar do recente incremento de pessoal na Divisa, o município de Fei- ra de Santana ainda está distanciado de uma política de desenvolvimento de recursos humanos em vigilância sanitária que explicite as suas especificidades, metas, estratégias e recursos necessários para o adequado cumprimento das suas responsabilidades como uma ação de proteção e defesa da saúde da população.

No final de 2000, o contrato entre a SMS e a Fundação (responsável pela sublocação de servidores temporários) foi rompido unilateralmente, culminando com a rescisão dos contratos dos referidos servidores. O clima de instabilidade provocou um "total esfriamento" nas atividades da Divisa, corroborando com o fato de que a instabilidade funcional é um importante fator indutor da descontinuidade das ações de vigilância sanitária no município.

Diante de tantos percalços e descompassos, salientamos, mais uma vez, que a indefinição de uma política de recursos humanos para a Divisão de Vigilância Sanitária, assim como para a SMS como um todo, se constitui num dos principais entraves ao avanço do processo de descentralização das ações de Visa no município, aliado às interferências político-partidárias, que encontram nos períodos pré-eleitorais terrenos férteis para a reprodução de interesses clientelistas que acabam resultando em prejuízos à saúde da coletividade.

\section{Os dilemas e desafios das novas responsabilidades da vigilância sanitária}

Foi possível captar no conteúdo discursivo a indefinição de um projeto político para que o município pudesse assumir efetivamente as responsabilidades referentes às ações básicas de vigilância sanitária. E, se não existe um projeto político definido para o repasse dessas ações, isto significa que o movimento vem se constituindo ao sabor dos (des)interesses dos atores sociais que estão à frente das instituições do nível municipal e estadual.

Embora o município estivesse em condições de assumir o repasse das ações de vigilância sanitária, há que se levar em conta que a descentralização, como um processo, consiste num movimento social, de natureza essencialmente dialética; tratando-se de um fato político de redistribuição de poder que se inscreve freqüentemente numa arena de luta política, permeada por interesses diversos. E, como refere Mendes (1996), falar de processo social implica reconhecer a complexidade de uma cons- 
trução que se dará em ambiente habitado por diversidade de representações de interesse e em campos sociais de diferentes hierarquias, quais sejam, o politico, o cultural e o tecnológico.

Isto posto, detectamos que a forma de encarar esse processo não foi compartilhada pelos sujeitos do estudo, ao reconhecer que o processo de descentralização das ações de vigilância sanitária não foi adequadamente planejado, e que, apesar da falta de condições estruturais, a Divisa foi forçada a assumir "bruscamente"o repasse das ações referentes às farmácias (drogarias) e serviços de saúde (consultórios).

Mas afinal de quem é a responsabilidade pelo planejamento e efetivação deste processo? Por onde anda o chamado pacto solidário, a co-responsabilidade e o sentido da cooperação técnica? Quem são os atores sociais que poderiam reverter esta situação?

Os sujeitos referiram, ainda, uma (des)articulação entre a SMS/Divisa e a 2a Dires, caracterizada por uma relação conflituosa, atribuindo este tipo de atitude à perda de poder técnico e político por parte do órgão regional, que historicamente manipulava os cordéis da saúde no município. Essa fragmentação entre as duas esferas administrativas (municipal e estadual) no processo de gestão do sistema público de saúde também foi enfocada nos estudos de Assis (1998a; 1998b). Este as caracterizou como espaços de disputas de interesses, em que os ocupantes de cargos são assegurados pelas indicações político-partidárias que ora se encontram no poder. Cada esfera administra seus espaços institucionais sem haver articulação de uma com a outra.

Desta situação é possível depreender que o avanço do processo de descentralização vem impondo uma necessidade premente de redefinição do papel dos três níveis de poder (central, regional e municipal). A Dires, nesse contexto, passa a desempenhar uma função de cooperação técnica com os municípios, constituindo-se numa ponte entre o nível local e o central, contribuindo, dessa forma, para a consolidação e integração do sistema de saúde (Bahia, 1998).

Mostra-se evidente que a gestão das ações de vigilância sanitária, tendo a descentralização como eixo orientador, depende essencialmente, dentre outros aspectos, da clareza e definição de papéis e atribuições dos principais atores sociais envolvidos neste processo - SMS/2a Dires -, bem como o reconhecimento de que é necessária a incorporação de uma atitude de co-responsabilidade na construção de um sistema de saúde integral que visa, acima de tudo, à garantia do direito à saúde.

Contudo, a realidade concreta, vivenciada pelos sujeitos, revela os nós críticos desse processo, que já haviam sido diagnosticados pelo próprio nível central (Diretoria de Vigilância e Controle Sanitário), que engendrou alguns movimentos com o objetivo de contornar essa situação. Nesse sentido, a Secretaria de Saúde da Bahia, através da Diretoria de Vigilância e Controle Sanitário, com o objetivo de construir as diretrizes para o aperfeiçoamento do modelo de gestão na área de Vigilância no Estado, promoveu, em 1998, alguns fóruns de discussão, como a Oficina de Descentralização das Atividades de Vigilância Sanitária (Oficina de Mamelucos), seguida das Oficinas de Capacitação para a Descentralização das Ações de Vigilância da Saúde, no mesmo ano (Bahia, 1999).

Essas iniciativas, evidentemente, ampliam as possibilidades de uma maior integração entre os três níveis de atuação em vigilância sanitária (central, regional e municipal), ao tomar por referência o delineamento de um processo de supervisão, envolvendo as equipes regionais e capacitando-as para lidar com os novos desafios impostos pela municipalização.

Outro aspecto considerado relevante pelos entrevistados se refere à conjugação de esforços da Divisa com outros atores sociais de grande relevância para a efetivação das suas ações, considerando a complexidade que envolve o campo da vigilância sanitária, as suas interconexões e o caráter transdisciplinar dos seus objetos de controle. Vale destacar a parceria entre a Divisa e o Ministério Público, uma vez que a atuação de ambos converge para a defesa e a proteção da saúde; a Divisa, através do controle sanitário de bens, produtos e serviços a serem consumidos pela população, e o Ministério Público assegurando à coletividade a defesa da ordem jurídica, do regime democrático e dos interesses sociais e individuais indisponíveis, tendo a função de zelar pelo efetivo respeito dos serviços de relevância pública aos direitos assegurados na Constituição, promovendo as medidas necessárias a sua garantia (Brasil, 1996b). A parceria com a academia também representou um aspecto positivo na condução das atividades da Divisa. 


\section{Infra-estrutura e ampliação do raio de ação}

Com relação à estrutura organizativa, a Divisa passou a conformar um novo cenário, como apontam, de forma convergente, os depoimentos dos técnicos e gestores entrevistados. Em termos de infra-estrutura, a Divisa passou a contar com alguns recursos, como equipamentos, veículo para ação fiscalizadora, ampliação da área física, dentre outros, necessários para viabilizar a sua atuação diante das novas responsabilidades assumidas pelo município, com o desencadeamento do processo de descentralização das suas ações.

Ainda que sejam reconhecidos os avanços ocorridos, como a ampliação do espaço físico, incremento de pessoal de nível médio e superior, aquisição de veículo e equipamentos, articulações interinstitucionais e o recebimento do incentivo financeiro (PBVS), constatamos que a Divisa continuava apresentando uma série de entraves estruturais ao desenvolvimento das suas ações.

Outro limite apontado pelos entrevistados se refere à dificuldade de acesso às informações referentes aos serviços e produtos sujeitos à fiscalização sanitária. A inexistência de um sistema de informações em vigilância sanitária, articulado com os demais sistemas de informação em saúde, obstaculariza a sua função de controle da situação sanitária e do monitoramento dos diversos fatores de riscos à saúde da população.

As interferências do judiciário e do Sindicato dos Farmacistas nas ações de vigilância sanitária foram, também, outro limite verbalizado pelos sujeitos deste estudo. Por intermediar a conflitante relação de produção-consumo, através do controle sanitário de bens, produtos e serviços, a vigilância sanitária torna-se alvo das mais diversas formas de pressão, advindas dos vários setores da sociedade.

Esse tipo de interferência sempre acompanhou a evolução dos serviços de vigilância sanitária no Brasil conforme Souto (1996), Costa (1998; 1999ab), complementado por Luchese (1992): área crítica das relações entre Estado e Sociedade, por envolver altos interesses econômicos e políticos, a Vigilância Sanitária sofreu as mais variadas formas de pressões políticas, oriundas do próprio executivo, ou provenientes do legislativo e mesmo do judiciário.

Apesar dos vários descompassos e entraves ao processo de descentralização das ações de vigilância sanitária já mencionados, ocorreram alguns avanços no desenvolvimento das atividades da Divisa conforme convergência dos depoimentos com relação ao cadastramento dos estabelecimentos sujeitos à ação de vigilância sanitária. O cadastramento dos estabelecimentos alvo das ações de controle sanitário é um dos requisitos básicos para o planejamento das atividades a serem desenvolvidas pelos serviços de Visa, no sentido de orientar a elaboração do plano de trabalho, o dimensionamento do quadro de pessoal e dos recursos necessários. Contudo, a Divisa não tinha conhecimento acerca deste quantitativo no município, cujo levantamento só foi efetivado no final do ano 2000 , contabilizando um total de 6.683 estabelecimentos. A conclusão dessa etapa pela equipe da Divisa gerou um conjunto de informações essenciais para subsidiar o planejamento das ações de vigilância sanitária a serem desenvolvidas no município, assim como foi uma das ações pactuadas para o ano 2000.

A Divisa cumpriu também a pactuação assumida com as instâncias do SUS (Sesab/CIB), por ter sido considerada uma das prioridades da vigilância municipal. De acordo com os documentos consultados o município negociou e pactuou as seguintes ações, apresentadas no quadro 4.

A realização de coletas de amostras referentes a alimentos, medicamentos e saneantes, pactuadas pela Divisa, introduz um novo enfoque no desenvolvimento das suas ações, o de avaliação da qualidade de produtos que podem colocar em risco a saúde da população/consumidor, ultrapassando, dessa forma, a prática de fiscalização sanitária restrita às instalações físicas, à emissão de licenças ou alvarás e à verificação das condições do exercício profissional.

Além do cadastramento, outro avanço alcançado pela Divisa refere-se à sua produtividade. O aumento do índice de produtividade pode ser justificado pela ampliação das ações sob a responsabilidade da Divisa a partir de 1999, quando foi iniciado efetivamente o repasse dessas ações, além da incorporação de novos agentes na Divisão. O quadro 5 apresenta os principais procedimentos realizados pela Divisa em 2000.

Dentre os procedimentos, observa-se, no quadro 5 , um elevado número de notificações contra estabelecimentos (2.338) e de produtos apreendidos (mais de 51 mil quilos de alimentos), 10.811 unidades de medicamentos/imunobiológicos, o que denota a crescente atuação da equipe da Divisa no município. Chama a 
Quadro 4

Ações pactuadas pela Divisa-2000. SMS, Feira de Santana. 2000.

\begin{tabular}{ll}
\hline Ações Pactuadas & Ações Cumpridas \\
\hline Cadastramento de estabelecimentos alvos da DIVISA & Foram cadastrados 6.683 estabelecimentos \\
$\begin{array}{l}\text { Coleta de Amostras } \\
\quad \text { Monitoramento da qualidade da água }\end{array}$ & Coletadas 200 amostras \\
para consumo humano -50 amostras/mês & \\
Alimentos: 20 amostras/ano & Coletadas 12 amostras \\
Medicamentos: 5 amostras/ano & Coletadas 4 amostras \\
Saneantes domissanitários $1: 4$ amostras/ano & Coletadas 4 amostras \\
\hline
\end{tabular}

Fonte: SMS - Relatório de Gestão 2000 - DIVISA Relatório de Atividades - 2000

Nota: As amostras foram coletadas no período de 4 meses (agosto a novembro)

1 Substâncias ou preparações destinadas a higienização, desinfecção ou desinfestação domiciliar,

em ambientes coletivos e/ou públicos, em lugares de uso comum e no tratamento da água, compreendendo:

inseticidas, raticidas, desinfetantes e detergentes (Brasil, 1976).

atenção o número de alvarás requeridos (2.338) em relação aos expedidos (138), refletindo adoção de uma conduta criteriosa na liberação de um instrumento que permitirá o funcionamento de um estabelecimento sujeito ao controle sanitário. Ressaltamos o número de queixas e denúncias por parte da população (738) ou de produtores/prestadores de serviços, dando indícios de reconhecimento de um órgão que, historicamente, vem buscando proteger e promover a saúde dos munícipes feirenses.

Quanto às atividades realizadas pela Divisa em 2000, ressaltam as ações educativas e de informação sanitária. Buscando uma maior aproximação com a comunidade, no intuito de divulgar a importância das ações de Visa para a proteção da saúde da população, foram realizadas várias palestras em escolas, Sindicato dos Panificadores, Farmacistas e Vendedores Ambulantes (Feira de Santana, 2000b).

Além dessas, foram realizadas atividades de fiscalização em feiras-livres e em eventos populares em parceria com a Fiscalização Preventiva Integrada (FPI) - comissão formada por representantes de diversos órgãos e instituições locais que desenvolvem ações conjuntas no município. Isto possibilitou o exercício da ação fiscalizadora indispensável para o alcance da efetividade das ações de Visa, compreendendoa como uma prática não apenas verificadora do cumprimento de normas, como também uma oportunidade de realização de ações educativas e orientadoras que devem permear todo o seu processo de trabalho.

Como foi visto, no decorrer desse período (1998-2000) o processo de descentralização das

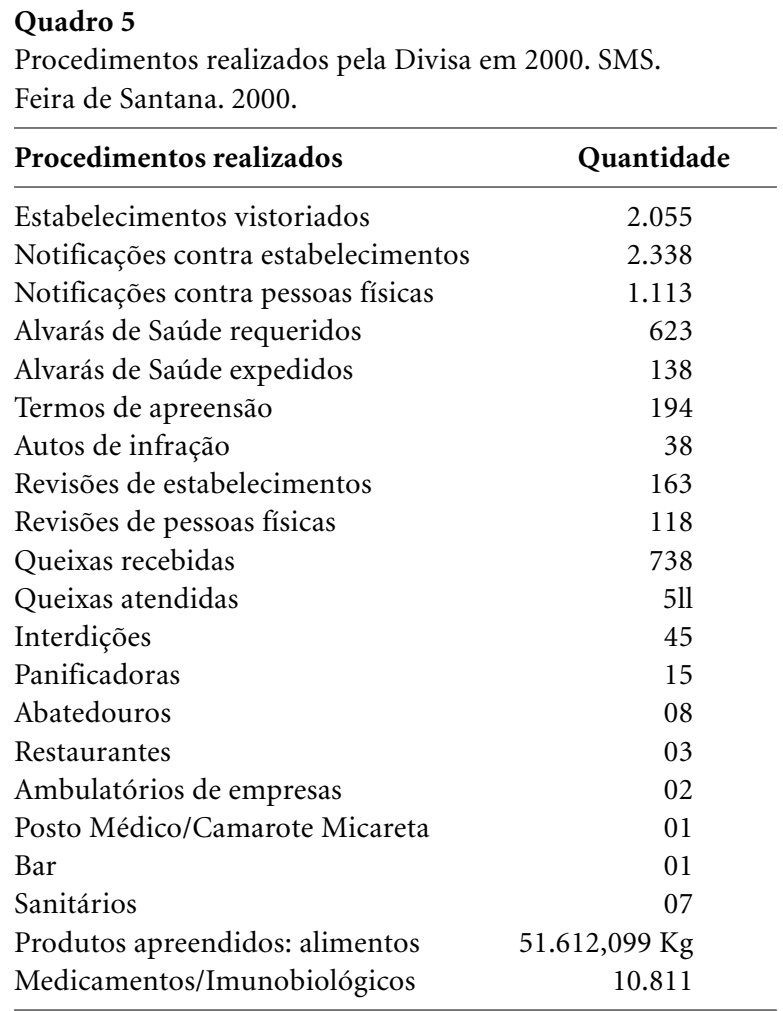

Fonte: SMS. DIVISA - Relatório de Atividades 2000.

ações de vigilância sanitária, ainda que incipiente e de forma (des)articulada com a instância regional, começa a se delinear a partir do recebimento do PBVS (1998) e da entrada em cena de sujeitos sociais comprometidos com as questões que permeiam a construção do SUS. Em 2000, a Divisa passa a conformar um novo cenário através da aquisição de recursos mate- 
riais, ampliação de espaço físico e incremento de pessoal, embora com vinculação temporária, aumento da demanda de ações, articulações interinstitucionais e uma maior aproximação do componente municipal de vigilância sanitária com a população.

Os sujeitos do estudo manifestaram algumas perspectivas com relação à continuidade do processo de descentralização das ações de Visa. Os relatos dos entrevistados convergiram no sentido de que os atores sociais que irão assumir o comando político-administrativo do município necessitam ter clareza e, acima de tudo, conhecimento acerca das questões que permeiam o sistema de saúde, não só no município, como em todo o país. E que reconheçam ainda a importância das ações de natureza preventiva, inerentes à vigilância sanitária, tornando-as prioritárias nas políticas de saúde a serem implementadas. Há consenso, por parte dos envolvidos, em que as indicações dos cargos de provimento temporário devem ser orientadas por critérios técnicos-científicos, de qualificação profissional e não por interesses clientelistas ou de nepotismo, tão comum em todas as esferas de poder.

\section{Considerações finais}

O estudo evidenciou que o processo de descentralização em Feira de Santana no período estudado representa um avanço, mas que o incentivo financeiro recebido pelo município, de acordo com a convergência dos depoimentos dos sujeitos, não era utilizado exclusivamente para o custeio das ações de vigilância sanitária, necessitando que seja instituído, o mais breve possível, um sistema de acompanhamento e avaliação do uso deste recurso pelo município.

Uma das formas previstas de avaliação seria através da base de dados do Sistema de Informações Ambulatoriais do SUS (SIA/SUS), que muitos municípios já estão alimentando; Feira de Santana, porém, até o final deste estudo (dezembro de 2000) não apresentava nenhum registro no Sistema de Informações (Datasus). Estas informações forneceriam subsídios para a avaliação das ações de vigilância sanitária executadas pelo município após o recebimento do PBVS. Contudo, o processo ainda carece de avaliação e aperfeiçoamento do ponto de vista da sua eficiência/eficácia, dado o caráter restritivo dos procedimentos codificados pelo sistema.

A análise retratou a ausência de um projeto político para uma gestão descentralizada das ações de Vigilância Sanitária no município, que se reflete na falta de prioridade nas políticas de saúde local, caracterizando-se como ações isoladas e desarticuladas das demais práticas sanitárias.

É imprescindível, para o avanço do processo de descentralização das ações de vigilância sanitária em Feira de Santana, encontrar formas eficientes de diálogo entre os níveis municipal, regional e estadual, de modo que sejam superados os entraves político-administrativos que ainda persistem. Para tanto, é necessária maior nitidez dos diferentes papéis dos diversos atores sociais que estão presentes no sistema de saúde no contexto atual.

O estudo acena para a necessidade de mobilização de sujeitos sociais com capacidade de vocalização para repensar a política de descentralização da vigilância sanitária em nível local que defina claramente os objetivos, as metas, os programas, a estratégia de implantação e implementação das ações, inscrevendo-a numa agenda de prioridades, buscando superar os limites e impulsionar os avanços. Assim, concordamos com Costa (1999b) quando esta afirma que "a saúde da população como um todo exige que as Políticas de Vigilância Sanitária componham o conjunto das políticas de saúde que se quer transformar".

Mas ainda são muitos os dilemas e desafios que permeiam o processo de descentralização das ações de Visa em Feira de Santana, a serem enfrentados pelos novos sujeitos que forem incorporados ao sistema, caracterizado por variações cíclicas de avanços e recuos, a depender dos interesses políticos e das relações estabelecidas entre os atores sociais responsáveis pela sua efetivação. Os desafios estão postos. E que diante deles seja possível lembrar da antiga máxima romana: A saúde do povo é a suprema lei. 


\section{Referências bibliográficas}

Andrade LOM 2001. SUS passo a passo. Normas, gestão e financiamento. Hucitec-UVA, São Paulo-Sobral.

Arretche M 2003. Financiamento federal e gestão local de políticas sociais: o difícil equilíbrio entre regulação, responsabilidade e autonomia. Ciência \& Saúde Coletiva 8(3):331-345.

Assis MMA 1998a. A municipalização da saúde: intenção ou realidade? Análise de uma experiência concreta. Universidade Estadual de Feira de Santana. Feira de Santana.

Assis MMA 1998b. As formas de produção dos serviços de saúde: o público e o privado. Tese de doutorado. Escola de Enfermagem de Ribeirão Preto. Universidade de São Paulo. Ribeirão Preto.

Bahia 1998. Secretaria da Saúde do Estado da Bahia. Assessoria de Planejamento, Programação e Orçamentação. Programação Pactuada e Integrada. CENDRHUDICOD, Salvador.

Bahia 1999. Secretaria de Saúde do Estado (SESAB). Divisão de Vigilância e Controle Sanitário. Uma proposta de Supervisão para a Divisa. Salvador.

Brasil 1976. Anvisa. Lei no 6.360, de 23 de setembro de 1976. Dispõe sobre a vigilância sanitária a que ficam sujeitos os medicamentos, as drogas, os insumos farmacêuticos e correlatos, cosméticos, saneantes e outros produtos, e dá outras providências. Publicada no D.O.U. de 24/9/1976. Disponível em <anvisa.gov. br>. Acesso em 20 de maio de 2004.

Brasil 1994. Ministério da Saúde. Portaria n. 1.565, de 26 de agosto de 1994. Define o Sistema Nacional de Vigilância Sanitária e sua abrangência, esclarece a competência das três esferas de governo e estabelece as bases para a descentralização da execução de serviços e ações de vigilância em saúde no âmbito do Sistema Único de Saúde.

Brasil 1996a. Ministério da Saúde. Norma Operacional Básica do SUS 01/96. Diário Oficial da União, n. 170, 21 set.

Brasil 1996b Constituição 1988. Constituição da República Federativa. Revista dos Tribunais, São Paulo.

Brasil 1999a. Lei no 9.782, de 26 de janeiro de 1999. Define o Sistema Nacional de Vigilância Sanitária, cria a Agência Nacional de Vigilância Sanitária, e dá outras providências. Diário Oficial da União, Brasília, seção 1, no 18, 27 jan.

Brasil 1999b. Ministério da Saúde/Secretaria de Assistência à Saúde. Manual para Organização da Atenção Básica. Ministério da Saúde, Brasília.

Brasil 2000. Comissão Nacional de Ética em Pesquisa. Normas para pesquisa envolvendo seres humanos. Ministério da Saúde, Brasília.

Brasil 2001. Ministério da Saúde.Secretaria de Assistência à Saúde. Situação atual do processo de habilitação. Disponível em <http://www.saúde.gov.br $>$. Acesso em 25 jul.

Brasil 2002. Ministério da Saúde. Reduzindo as desigualdades e ampliando o acesso à assistência à saúde no Brasil (1998-2002). Ministério da Saúde, Brasília.

Carvalho GI \& Santos L 1995. Sistema Único de Saúde: comentários à Lei Orgânica da Saúde (8.080/90 e 8.142/ 90). (2a ed.). Hucitec, São Paulo.
Costa EA 1998. Vigilância sanitária: defesa e proteção da saúde. Tese de doutorado em Saúde Pública. Faculdade de Saúde Pública, Universidade de São Paulo. São Paulo.

Costa EA 1999a. Vigilância sanitária: defesa e proteção da saúde, pp. 327-352. In MZ Rouquayrol. Epidemiologia é saúde. (5a ed.). MEDSI, Rio de Janeiro.

Costa EA 1999b. Vigilância sanitária: proteção e defesa da saúde. Hucitec-Sobravime, São Paulo.

Feira de Santana (Bahia) 1997. Secretaria Municipal de Saúde. Plano Municipal de Saúde 1998-2001. Feira de Santana.

Feira de Santana (Bahia) 2000a. Câmara Municipal. Lei Orgânica do Município n. 037, de 5 de abril de 1990 (atualizada até junho de 2000). Feira de Santana.

Feira de Santana (Bahia) 2000b. Prefeitura Municipal de Feira de Santana. Secretaria de Planejamento (SEPLAN) - Departamento de Informações de Estatísticas. Relatório de Atividades 1999-2000. Feira de Santana.

Instituto Brasileiro de Geografia e Estatística (IBGE) 2003. Censo demográfico 2000. Disponível em: <http:// www.ibge.br $>$ Acesso em: 19 de setembro.

Juliano IA 1999. Projeto de Reestruturação da Divisão de Vigilância Sanitária Municipal - PRODIVISA. Secretaria Municipal de Saúde. Feira de Santana.

Luchese G 1992. Vigilância sanitária: o elo perdido. Divulgação em Saúde para Debate 7:48-52.

Lüdke M \& André MED. 1986. Pesquisa qualitativa em educação: abordagens qualitativas. EPU, São Paulo.

Martins ACP \& Assis MMA 2002. Servicos de saúde (públicos e privados) de Feira de Santana-BA. UEFS Feira de Santana. (Digitado).

Médici AC et al.1992. Mercado de trabalho em saúde no Brasil: estrutura e conjuntura (Textos de Apoio). ENSP Rio de Janeiro.

Mendes EV 1996. Uma agenda para a saúde. Hucitec, São Paulo.

Minayo MCS1994. O desafio do conhecimento: pesquisa qualitativa em saúde. (3a ed.). Hucitec, São Paulo.

Soares LT 2000. Os custos sociais do ajuste neoliberal na América Latina.. Cortez, São Paulo.

Souto AC 1996. Saúde e política: a Vigilância Sanitária no Brasil - 1976-1994. 1996. Dissertação de mestrado em Saúde Comunitária. Instituto de Saúde Coletiva da Universidade Federal da Bahia. Salvador.

Ugá AM et al. 2003. Descentralização e alocação de recursos no âmbito do Sistema Único de Saúde (SUS). Ciência \& Saúde Coletiva 8(2):417-437.

Viana ALD, Lima LD \& Oliveira RG 2002. Descentralização e federalismo: a política de saúde em novo contexto - lições do caso brasileiro. Ciência \& Saúde Coletiva 7(3):1-15. Disponível em <www.scielo.br/re vistas/csc/paboutj.htm>. Acesso em 21 de jul. de 2003.

Artigo apresentado em 18/11/2002

Aprovado em 29/12/2002

Versão final apresentada em 20/5/2003 